Research article

\title{
Multi-route - Multi-pathway exposure to trihalomethanes and associated cumulative health risks with response and dose addition
}

\author{
Mesut Genisoglu, Ceyda Ergi-Kaytmaz ${ }^{1}$, Sait C. Sofuoglu* \\ Izmir Institute of Technology, Department of Environmental Engineering, Gulbahce, Urla, 35430, Izmir, Turkey
}

\section{A R T I C L E I N F O}

\section{Keywords:}

Cumulative risk

Exposure assessment

Health risk assessment

Trihalomethanes

\begin{abstract}
A B S T R A C T
Cumulative health risk estimation for exposure to mixtures is a current issue, which would present a useful tool for environmental and public health management. Cumulative risks were estimated with response and dose addition methods for individual multi-route - multi-pathway exposure to trihalomethanes and associated carcinogenic toxic risks in Izmir, Turkey. Exposure levels were estimated for ingestion, dermal, and inhalation routes using measured tap water and bottled water THM concentrations. Drinking, showering, hand and dish washing were the considered pathways. THM concentrations in air during the showering were modeled with two-resistance theory using tap water concentration data. The estimated carcinogenic risk levels for ingestion route were in the range of safe $\left(<10^{-6}\right)$ to low priority $\left(<10^{-4}\right)$, for dermal route all were in the safe zone $\left(<10^{-6}\right)$, and for inhalation route were in the range of safe to high priority $\left(>10^{-4}\right)$ zones, indicating ingestion and inhalation routes were of similar significance ahead of dermal exposure. Cumulative carcinogenic risks of THM compounds were estimated using simple (response) addition and dose addition using cumulative relative potency factor (CRPF) methods. CRPF method estimated the risks at lower levels compared to the simple addition, which originated from the use two different risk factor values for the index chemical in the method. Cumulative chronic-toxic risks were also assessed, rendering below the threshold risk levels for all routes. This study showed that multi-route - multi-pathway exposure assessment and cumulative risk assessment should together be considered for better environmental and public health management.
\end{abstract}

\section{Introduction}

Chlorine is the most commonly used disinfectant due to its various advantages to prevent waterborne diseases such as cholera, typhoid, dysentery, and diarrhea (Legay et al., 2011; Kinani et al., 2016). However, the reaction of chlorine and natural organic matter forms disinfection by-products (DBPs). DBPs are formed up to 700 species as a result of reactions between the disinfectant and precursors, such as natural organic matter (NOM), algal organic matter (AOM), bromide, iodide, nitrite, etc., in disinfection processes (Krasner, 2009; Stalter et al., 2016). Among them, THMs attracted attention and became the most studied group because they occur with the highest concentrations and the highest frequencies (Nazir and Khan, 2006). Therefore, THMs are considered to be indicators of chlorinated DBPs (Villanueva et al., 2004). The THM group consists of $\mathrm{CHCl}_{3}$ (chloroform), $\mathrm{CHCl}_{2} \mathrm{Br}$ (bromodichloromethane, $\mathrm{BDCM}$ ), $\mathrm{CHClBr}_{2}$ (dibromochloromethane, $\mathrm{DBCM}$ ), and $\mathrm{CHBr}_{3}$ (bromoform).

Long term exposure to THMs may pose health risks to human beings. Epidemiological studies have shown a relationship between exposure to chlorinated drinking water and likelihood of bladder cancer in men (Villanueva et al., 2004). Although it is a carcinogen, it was decided that carcinogenic effects are unlikely for chloroform at common drinking water concentrations, resulting in withdrawal of its carcinogenic risk factor from Integration Risk Information System (IRIS) (USEPA, 2018) by United States Environmental Protection Agency (USEPA) deeming the Reference Dose (RfD) is sufficient. Carcinogenicity studies on bromoform have shown that there is a positive association between bromoform and cancer in humans, but these studies are incomplete (USEPA, 2018). However, animal studies have provided evidence that bromoform is carcinogenic. Bromoform, increases the activity leading to tumor formation in the liver and skin (Pereira et al., 1982). Although there is no epidemiological study for BDCM alone, there are some studies that show relationship between chlorinated drinking water and cancer (Cantor et al., 1978, 1987; Aldrich and Peoples, 1982). Studies with BDCM on animals show that BDCM increases formation of liver, kidney and intestinal tumors

\footnotetext{
* Corresponding author.

E-mail addresses: cemilsofuoglu@iyte.edu.tr, saitcemil@iit.edu (S.C. Sofuoglu).

${ }^{1}$ Present address: THY OPET Aviation Fuels, Bakirkoy, Istanbul.
} 
(USEPA, 2018). Although there is no epidemiological study that DBCM is carcinogenic to humans and there is limited evidence for carcinogenic to animals, the case of hepatocellular adenomas and carcinomas were significantly increased in female mice (USEPA, 2018). Maximum contaminant level (MCL) of THMs is limited to $80 \mu \mathrm{g} / \mathrm{L}$ and $100 \mu \mathrm{g} / \mathrm{L}$ by USEPA (USEPA, 2006) and Turkish Legislation (Official Gazette, 2013), respectively.

Exposure to THMs may occur through ingestion, dermal contact, and inhalation. Consumption of drinking water is the main ingestion exposure pathway. Hand washing, dishwashing, and showering are the regular daily activities that cause dermal contact to THMs in tap water, among which showering is the main regular activity for inhalation route (Nazir and Khan, 2006). THM concentrations in air of indoor swimming pools, hot tubs, and bathrooms are generally higher due to their relatively high vapor pressures (Harman et al., 2017). THM concentrations in water and air is increased with increasing water temperature. The temperature effect is related to two mechanisms: (i) THM growth and (ii) air-water partitioning described by Henry's Law constant (Chowdhury and Champagne, 2009). THM formation may increase with increasing ambient temperature as a result of increasing reaction rates between residual chlorine and organic matter (Chowdhury and Champagne, 2009). Hua and Reckhow (2008) reported that total organic halogen (TOX) and THM concentrations increase with temperature due to the temperature dependence of halogenation reaction. In addition, Henry's Law constant is temperature dependent. Consequently, mass transport of THMs from water to air is increased with increasing temperature (Nicholson et al., 1984).

Like many studies in the literature, exposure and health risks were underestimated by our previous study for Izmir due to the lack of gas phase concentrations, ignoring inhalation pathway (Kavcar et al., 2006). However, exposure via inhalation is relatively high due to the volatility of THMs, which may be as important as ingestion exposure. Previous studies showed that inhalation exposure may be up to 6 times higher than the ingestion route (Lin and Hoang, 2000). Showering was determined as the main exposure inhalation pathway compared to cooking and dish washing (Lin and Hoang, 2000). Gas phase levels have been estimated by modeling volatilization from heated water such as used in bathing and hot tubs (Chowdhury and Champagne, 2009).

There are several studies in the literature claiming that inhalation and dermal exposure constitute serious health risks in addition to oral exposure (Lee et al., 2004; Siddique et al., 2015). Inhalation exposure distinguish further because of the volatility of THMs (Lin and Hoang, 2000; Thiriat et al., 2009; Pan et al., 2014; Niu et al., 2015), which has been shown to exceed dermal and ingestion exposures (Basu et al., 2011; Pardakhti et al., 2011). For this reason, estimation of multi-route exposure to THMs is important, while estimation of cumulative risks associated with the four potent THM species is also critical, which may lead the local authorities to adopting stringer standards of their own to better protect the population they serve. The cumulative cancer risks of THMs is usually calculated summing the component responses, i.e., risk levels (simple addition method) (Lee et al., 2004; Wang et al., 2007a; b; Viana et al., 2009; Siddique et al., 2015). Dose addition has also been considered. Cumulative Relative Potency Factor (CRPF) approach was developed based on combining dose and response additions (Teuschler et al., 2004). CRPF approach could be used for estimation of the cumulative cancer risk of DBP mixture, dividing the DBP components to subclasses and selecting an index component for each subclass. Their doses are converted to index chemical equivalents using the RPFs, similar to Toxic Equivalency Factors that have been used for pollutants such as polycyclic aromatic hydrocarbons, dioxins, and dioxin-like polychlorinated biphenyls (Gungormus et al., 2014; Ugranli et al., 2016; Dumanoglu et al., 2017; Cetin et al., 2018). Then, the risk factor of the index chemical is used to calculate the risk associated with the calculated total dose of the subclass. The use of CRPF approach was suggested by Lambert and Lipscomb (2007) and Gallagher et al. (2015).

Determining the cumulative risks of mixtures such as DBPs has been an important issue in the last two decades. USEPA has been leading the efforts (Choudhury et al., 2000; USEPA, 2000, 2002, 2003). However, there is no study that estimated and compared the carcinogenic risks by using both of the simple addition and CRPF methods other than those developed and suggested the use of CRPF. The aim of this study was to estimate and compare cumulative health risks of THMs estimated by CRPF and simple addition methods using our previously reported THM levels in drinking water of Izmir, Turkey (Kavcar et al., 2006), which still can be of use according to the measurements made by the local authorities. This is, according to our knowledge, the first study that compared simple addition and CRPF methods for cumulative carcinogenic risks. This is also the first assessment of multi-route - multipathway exposure to THMs and associated cumulative health risks in Izmir, Turkey, which may have important implications for environmental/public health management mitigation efforts.

\section{Material and methods}

\subsection{Sampling and THM analysis}

Kavcar et al. (2006) had collected samples from 100 households in Izmir, Turkey. While tap water was drunk in 65 of the 100 sampled households, the remaining 35 consumed bottled water. Bottled water samples were directly collected from the container. Tap water samples were collected after the 3 min flushing. Ascorbic acid was used as a quenching agent for inhibition of the oxidant activity. Sampling vials were immediately closed and shaken for mixing the sample and quenching agent. All samples were transferred to the laboratory in dark in a cooler, and extracted within five days. Gas chromatography instrument (Agilent 6890N) with a mass selective detector (Agilent 5973N MSD) was used for analysis of THMs. Five-point calibration (1, $5,25,50$, and $100 \mu \mathrm{g} / \mathrm{L}$ ) was used. $\mathrm{R}^{2}$ values of calibration curves were higher than 0.996. Further details can be found in the previous study (Kavcar et al., 2006). Total THM concentrations measured by the local authorities at several points in the water distribution system in 2013-2017 period were obtained to validate the use of previously measured concentrations by comparing the two sets by hypothesis testing.

\subsection{Concentration modeling}

THM concentrations increase with increasing water temperature while taking shower. Heated water THM concentrations are calculated using Equations (1) and (2) that were developed by Chowdhury and Champagne (2009).

$\mathrm{k}=0.0011 \times \mathrm{e}^{0.0407 \times \mathrm{T}}$

where, $k$ : THMs growth rate at $\mathrm{T}{ }^{\circ} \mathrm{C}\left(\mathrm{min}^{-1}\right)$; $\mathrm{T}$ : temperature of water $\left({ }^{\circ} \mathrm{C}\right)$.

$C_{h w}=C_{w} \times \mathrm{e}^{\left(k_{h w}-k_{w}\right) \times \mathrm{t}}$

where, $C_{h w}$ : THM concentration in heated water ( $\left.\mu \mathrm{g} / \mathrm{L}\right) ; C_{w}$ : THM concentration in tap water ( $\mu \mathrm{g} / \mathrm{L}) ; k_{h w}$ : THM growth rate of heated water $\left(\mathrm{min}^{-1}\right) ; k_{w}$ : THM growth rate of tap water $\left(\mathrm{min}^{-1}\right)$; $t$ : shower duration (min).

THM concentrations in air is estimated using the two-resistance theory (Eqs. (3)-(7)). A model developed by Little (1992) for modeling air concentrations based on measured water concentrations. Table 1 shows the specific values used in modeling the THM concentrations in air.

$$
\begin{aligned}
& Y_{S}(t)=[1-\exp (-b t)](a / b) \\
& b=\left\{\left(Q_{L} / H\right)[1-\exp (-N)]+Q_{G}\right\} / V_{S} \\
& a=\left\{Q_{L} C_{W}[1-\exp (-N)]\right\} / V_{S}
\end{aligned}
$$


Table 1

Parameter values used in modeling.

\begin{tabular}{|c|c|c|c|}
\hline Parameter & & & Reference \\
\hline \multirow[t]{4}{*}{$\mathrm{K}_{\mathrm{OL}} \mathrm{A}(\mathrm{L} / \mathrm{min})$} & Chloroform & 7.4 & \multirow{4}{*}{$\begin{array}{l}\text { Wang et al., 2007a, } \\
\text { b }\end{array}$} \\
\hline & BDCM & 5.9 & \\
\hline & DBCM & 4.6 & \\
\hline & Bromoform & 3.7 & \\
\hline $\mathrm{Q}_{\mathrm{L}}(\mathrm{L} / \mathrm{min})$ & & 5 & \multirow[t]{3}{*}{ Little, 1992} \\
\hline Vs $\left(\mathrm{m}^{3}\right)$ & & 6 & \\
\hline $\mathrm{Qg}(\mathrm{L} / \mathrm{min})$ & & 50 & \\
\hline \multirow{4}{*}{$\begin{array}{l}\mathrm{H} \text { at } 40^{\circ} \mathrm{C} \\
\text { (dimensionless) }\end{array}$} & Chloroform & 0.350 & \multirow{4}{*}{$\begin{array}{l}\text { Nicholson et al., } \\
1984\end{array}$} \\
\hline & BDCM & 0.186 & \\
\hline & DBCM & 0.102 & \\
\hline & Bromoform & 0.058 & \\
\hline \multirow[t]{4}{*}{$\mathrm{Kp}(\mathrm{cm} / \mathrm{hr})$} & Chloroform & 0.16 & \multirow[t]{4}{*}{ Legay et al., 2011} \\
\hline & BDCM & 0.18 & \\
\hline & DBCM & 0.20 & \\
\hline & Bromoform & 0.21 & \\
\hline IRa (m3/hr) & inhalation & 20 & USEPA, 2011 \\
\hline IRw (1/day) & individual & - & Kavcar et al., 2006 \\
\hline EFh (day/year) & all routes & 350 & $\begin{array}{l}\text { assumed in this } \\
\text { study }\end{array}$ \\
\hline ED (year) & employed duration & 30 & $\begin{array}{l}\text { assumed in this } \\
\text { study }\end{array}$ \\
\hline ED (year) & $\begin{array}{l}\text { unemployed } \\
\text { duration }\end{array}$ & 40 & $\begin{array}{l}\text { assumed in this } \\
\text { study }\end{array}$ \\
\hline ED (year) & lifetime & 70 & USEPA, 2011 \\
\hline BW & individual & - & Kavcar et al., 2006 \\
\hline \multirow[t]{2}{*}{ Skin surface area $\left(\mathrm{m}^{2}\right)$} & body & individual & Livingston and Lee, \\
\hline & hand & individual & $\begin{array}{l}2001 \\
\text { USEPA, } 2011\end{array}$ \\
\hline
\end{tabular}

$N=\left(K_{O L} A\right) / Q_{L}$

$C_{a i r}=\left(Y_{s}(t)+Y_{s i}\right) / 2$

where, $Y_{S i}$ : initial THM concentration in shower room (assumed as 0 because we neglected inhalation exposure during activities other than showering); $Y_{S}$ : THM concentration in the shower at time t (min); $Q_{L}$ : water flow rate (L/min); $Q_{G}$ : Air flow rate $(\mathrm{L} / \mathrm{min}) ; V_{s}$ : bathroom volume $\left(\mathrm{m}^{3}\right) ; H$ : dimensionless Henry's law constant; $K_{O L} A$ : overall mass transfer coefficient $(\mathrm{L} / \mathrm{min})$.

\subsection{Exposure and risk assessment}

Individual multi-pathway carcinogenic and chronic toxic health risk assessment was conducted for THMs in tap/drinking water of Izmir, based on the USEPA guidance documents (USEPA, 1992). Exposure assessment was conducted for oral, dermal adsorption, and inhalation routes for different scenarios. Drinking the water is the main pathway for ingestion route. While showering and hand washing were assumed as the main pathways for the route of dermal adsorption, showering was considered as the main activity for inhalation exposure. Exposure to THMs was calculated using chronic daily intake (CDI). The CDI values were calculated for ingestion, dermal adsorption, and inhalation with Eq. (8), Eq. (9), and Eq. (10), respectively.

$C D I_{\text {ingestion }}=\frac{C_{w} * I R w * E F * E D}{B W * A T}$

$C D I_{\text {dermal }}=\frac{C_{w a} * K p * E T * E F * E D}{B W * A T}$

$C D I_{\text {inhalation }}=\frac{C_{a} * I R a * E T * E F * E D}{B W * A T}$

where, $C w$ : concentration in water (mg/L), IRw: ingestion rate of drinking water (L/day); $E F$ : exposure frequency (day/year); $E D$ : exposure duration (year); $S A$ : skin surface area $\left(\mathrm{cm}^{2}\right)$; $K p$ : specific permeability coefficient $(\mathrm{cm} / \mathrm{h})$; ET: exposure time (h); Ca: concentration in air $\left(\mathrm{mg} / \mathrm{m}^{3}\right)$; IRa: inhalation rate $\left(\mathrm{m}^{3} / \mathrm{h}\right) ; B W$ : body weight; $A T$ : average lifetime.
Table 2

SF and RfD values of THMs used in the risk calculations.

\begin{tabular}{lllll}
\hline \multirow{2}{*}{ THM } & SF (Ingestion) & SF (Dermal) & SF (Inhalation) & RfD \\
\cline { 2 - 5 } & $(\mathrm{mg} / \mathrm{kg} \text {-day) })^{-1}$ & & & $(\mathrm{mg} / \mathrm{kg}$-day) \\
\hline Chloroform & N.A. & $0.031^{\mathrm{b}}$ & $0.0805^{\mathrm{a}, \mathrm{c}}$ & $0.01^{\mathrm{a}}$ \\
BDCM & $0.062^{\mathrm{a}}$ & $0.062^{\mathrm{a}}$ & $0.13^{\mathrm{b}}$ & $0.02^{\mathrm{a}}$ \\
DBCM & $0.084^{\mathrm{a}}$ & $0.084^{\mathrm{a}}$ & N.A. & $0.02^{\mathrm{a}}$ \\
Bromoform & $0.0079^{\mathrm{a}}$ & $0.0079^{\mathrm{a}}$ & $0.00385^{\mathrm{a}, \mathrm{c}}$ & $0.02^{\mathrm{a}}$ \\
\hline
\end{tabular}

N.A.:Not available.

a USEPA, 2018.

b CalEPA, 2018.

c Derived from inhalation unit risk.

Carcinogenic risks were calculated with CDI and corresponding slope factor (SF) values (Eq. (11)). Hazard Quotient (HQ) was calculated for chronic-toxic risk assessment (Eq. (12)). Chronic-toxic risk analysis for inhalation route could not be performed since the RfC values for THM compounds are not yet evaluated. SF and RfD values used in the calculations, which were obtained from IRIS (USEPA, 2018) or if not available from CalEPA (2018), are listed in Table 2. Cumulative risk is the total risk associated with the simultaneous exposure to the mixture of THM compounds. It was estimated with two methods: (i) simple addition (SA), and (ii) CRPF method. The CRPF method was developed by Teuschler et al. (2004). Briefly, an index compound was selected (BDCM). Doses of other components in the subclass were converted to dose of index component (equivalent or relative dose) using "relative potency factors (RPF)". RPF is defined as the ratio of the risk factors of subject compound to the index compound. When dose of subject compound is multiplied by its RPF it is converted to Index Chemical Equivalent Dose (ICED). As shown in Eq. (13) and Eq. (14); ICEDs of each compound were summed and multiplied by "maximum likelihood estimate (MLE) of cancer slope factor of the index chemical". The MLE value was used as 0.0057 (Teuschler et al., 2004).

Risk $=C D I \times S F$

$H Q_{\text {ingestion } \text { or dermal }}=C D I / R f D$

$I C E D=\frac{S F_{a}}{S F_{i}} \times$ Dose $_{a}+\frac{S F_{b}}{S F_{i}} \times$ Dose $_{b}+\frac{S F_{c}}{S F_{i}} \times$ Dose $_{c}$

$C R=I C E D \times M L E$

where, CDI: chronic daily intake dose; $S F$ : slope factor; $H Q$ : hazard quotient; $R f D$ : reference dose; $S F_{a, b, c}:$ slope factors of a, b, and c compounds; $S F_{i}$ : slope factor of index compound; Dose ${ }_{a, b, c}:$ dose of a, b, and c compounds, ICED: index chemical equivalent dose; MLE: maximum likelihood estimate of the slope factor.

Three scenarios were constructed to estimate the exposure through ingestion: Scenario 1 (Scenario $1_{\text {ing }}$ ), drinking from tap water at both of home and work; Scenario 2 (Scenario 2 ing), drinking from tap water at home and bottled water at work; and Scenario 3 (Scenario $3_{\text {ing }}$ ), drinking from bottled water at both of home and work. The consumption amounts of drinking water were determined by Kavcar et al. (2006) by a questionnaire survey administered to people living in the sampled households. An individual exposure calculation was made for each study participant using the measured concentrations at their households and questionnaire survey data. Three scenarios were constructed to estimate the exposure through each of the inhalation and dermal pathways based on the activity durations. The upper-bound (95th percentile), mean, and median values of activity durations were selected as exposure durations through inhalation and dermal pathways for the construction of scenarios (Scenario $1_{\text {inhalation/dermal, Scenario }}$ $2_{\text {inhalation/dermal, }}$ and Scenario 3 inhalation/dermal, respectively). Showering was selected as the main activity that cause exposure through inhalation pathway. Body surface area values of the participants were calculated using an empirical model based on body weight developed by 
Table 3

THM concentrations in water and bathroom air.

\begin{tabular}{|c|c|c|c|c|c|c|}
\hline Water Source & & Chloroform & BDCM & DBCM & Bromoform & $\mathrm{THM}^{\mathrm{a}}$ \\
\hline \multirow[t]{4}{*}{ Bottled Water $(\mu \mathrm{g} / \mathrm{L})$} & Mean & 0.81 & 0.65 & 0.41 & 0.10 & 1.98 \\
\hline & $\mathrm{SD}^{\mathrm{b}}$ & 4.64 & 3.82 & 2.35 & 0.33 & 11.1 \\
\hline & Median & 0.02 & $<0.01$ & 0.01 & 0.06 & 0.09 \\
\hline & $\mathrm{Q} 1-\mathrm{Q} 3^{\mathrm{c}}$ & $<0.01-0.04$ & $<0.01-0.01$ & $<0.01-0.02$ & $0.03-0.07$ & $0.07-0.11$ \\
\hline \multirow[t]{4}{*}{ Tap Water $(\mu \mathrm{g} / \mathrm{L})$} & Mean & 6.35 & 5.38 & 3.80 & 0.90 & 16.4 \\
\hline & $\mathrm{SD}$ & 10.6 & 8.76 & 5.85 & 1.06 & 25.5 \\
\hline & Median & 0.11 & 0.13 & 0.35 & 0.40 & 1.20 \\
\hline & Q1-Q3 & $0.02-9.80$ & $0.02-7.25$ & $0.02-4.67$ & $0.07-1.80$ & $0.15-34.4$ \\
\hline \multirow[t]{4}{*}{ Heated Tap Water $(\mu \mathrm{g} / \mathrm{L})$} & Mean & 6.82 & 5.78 & 4.08 & 0.97 & 17.7 \\
\hline & $\mathrm{SD}$ & 11.3 & 9.41 & 6.28 & 1.13 & 27.4 \\
\hline & Median & 0.12 & 0.14 & 0.38 & 0.43 & 1.29 \\
\hline & Q1-Q3 & $0.02-10.5$ & $0.02-7.79$ & $0.03-5.02$ & $0.08-1.93$ & $0.16-36.9$ \\
\hline \multirow[t]{4}{*}{ Bathroom Air $\left(\mu \mathrm{g} / \mathrm{m}^{3}\right)$} & Mean & 40.3 & 30.2 & 18.2 & 3.66 & 92.4 \\
\hline & $\mathrm{SD}$ & 66.9 & 49.2 & 28.0 & 4.25 & 144 \\
\hline & Median & 0.70 & 0.73 & 1.68 & 1.62 & 5.43 \\
\hline & Q1-Q3 & $0.13-62.1$ & $0.09-40.7$ & $0.12-22.4$ & $0.29-7.31$ & $0.72-188$ \\
\hline
\end{tabular}

a THM, sum of chloroform, BDCM, DBCM, and bromoform.

b $\mathrm{SD}$, standard deviation; ${ }^{\mathrm{c}} \mathrm{Q} 1,25$ th percentile; ${ }^{\mathrm{C}} \mathrm{Q} 3,75$ th percentile value.

Livingston and Lee (2001). Surface area of hands was used for dermal exposure during hand and dish washing, calculated using surface area percentage values reported in Exposure Factors Handbook (USEPA, 2011). Individual body weights of participants were used in all scenarios.

\section{Results and discussion}

\subsection{THM concentrations}

Generally, chloroform is the most common DBP in chlorinated drinking waters (Uyak, 2006; Chowdhury, 2013; Gan et al., 2013). In this study, chloroform was identified as the highest concentration THM species as shown in Table 3. The mean and maximum concentrations in Izmir tap water were 6.35 and $34.6 \mu \mathrm{g} / \mathrm{L}$, respectively. The most abundant THMs after chloroform in Izmir tap water were BDCM and DBCM. Bromoform is usually found in chlorinated drinking waters at low concentrations (Uyak, 2006; Chowdhury, 2013; Gan et al., 2013). The mean and maximum concentrations of bromoform in Izmir tap water were 4.19 and $9.02 \mu \mathrm{g} / \mathrm{L}$, respectively. The mean concentration of total THMs in Izmir water is $16.4 \mu \mathrm{g} / \mathrm{L}$. The mean total THM concentration of bottled water was $1.98 \mu \mathrm{g} / \mathrm{L}$. Generally natural spring waters are bottled and released to the market for consumption in Turkey. NOM concentrations of spring waters are much lower than surface waters (Thomas and Burgess, 2017).

Because sampling of volatile organic compounds is expensive and labor-intensive, concentrations are measured only in water while indoor air gas-phase concentrations as a result of volatilization from chlorinated tap water are commonly estimated by modeling (Lin and Hoang, 2000; Nazir and Khan, 2006; Chowdhury and Champagne, 2009). Kavcar et al. (2006) did also measure THM concentrations only in water but not estimated the associated indoor air levels, which is mainly a concern during showering because water is heated and sprayed resulting in higher volatilization (Little, 1992). Water temperature is generally assumed as $40^{\circ} \mathrm{C}$ for showering in the literature (Nazir and Khan, 2006). THM growth rates depend on the water temperature (Chowdhury and Champagne, 2009). Growth rate model is used to model the increase in water THM concentrations depending on its temperature (Nicholson et al., 1984), which also increases volatilization (Batterman et al., 2000). Tap water and heated water temperatures were assumed as 15 and $40{ }^{\circ} \mathrm{C}$, respectively. The estimated bathroom air concentrations are listed in Table 3. The highest mean concentration was estimated for chloroform $\left(77.60 \mu \mathrm{g} / \mathrm{m}^{3}\right)$; however, the highest median concentrations belonged to DBCM and bromoform (2.88 and $2.56 \mu \mathrm{g} / \mathrm{m}^{3}$ ), which are higher than those of chloroform and
BDCM $\left(1.29\right.$ and $\left.1.27 \mu \mathrm{g} / \mathrm{m}^{3}\right)$.

The skewness of chloroform, BDCM, DBCM, and bromoform concentrations in tap water were determined as $1.47,1.35,1.25$, and 1.22, respectively. Skewness values of the concentrations of THM compounds in bottled water are in the range of 5.87-5.92. Positive skewness values indicated the distribution of concentrations are right-skewed for bottled water. Quartile coefficient of distribution (QCD) values of four THM compounds in tap water are in the range of $0.92-1.00$. Bottled water QCD values for chloroform, BDCM, DBCM, and bromoform are 0.91, $0.94,0.86$, and 0.33 , respectively, which indicate that bromoform variation in bottled water was lower than those of the other three compounds that have similar levels of variation. Skewness and QCD values of heated water and bathroom air concentrations of THMs are similar to those of tap water because they are modeled based on the tap water levels that have larger spread than bottled water.

\subsection{Multi-route - multi-pathway exposure}

Exposure scenarios were established to account for variation in the daily activities that are associated with exposure. The highest median exposure levels of chloroform, BDCM, DBCM, and bromoform through ingestion pathway were estimated in Scenario 1 as $2.08 \times 10^{-6}$, $3.65 \times 10^{-6}, 7.12 \times 10^{-6}$, and $7.81 \times 10^{-6} \mathrm{mg} / \mathrm{kg}$-day, respectively. The lowest median exposure levels of chloroform, BDCM, DBCM, and bromoform through ingestion pathway were estimated in Scenario 3 as $4.90 \times 10^{-7}, 1.09 \times 10^{-7}, 1.38 \times 10^{-7}$, and $1.39 \times 10^{-6} \mathrm{mg} / \mathrm{kg}$-day, respectively. Chowdhury et al. (2014) estimated the mean exposure levels of chloroform, BDCM, DBCM, and bromoform through ingestion pathway in the range of $2.65 \times 10^{-4}$ and $1.75 \times 10^{-5} \mathrm{mg} / \mathrm{kg}$-day in tap water. The THM exposure values calculated with the highest concentration and average concentration of THM compounds in tap water were estimated by Panyakapo et al. (2008) were in the range of $1.59 \times 10^{-3}-1.83 \times 10^{-4}$ and $7.59 \times 10^{-4}-8.07 \times 10^{-5}$, respectively. Compared with the literature; exposure levels of THM from the tap water of Izmir appears to be relatively low due to the relatively low THM concentrations. These concentrations are also lower than those measured at other cities of Turkey such as Istanbul in the range of $43-100 \mu \mathrm{g} / \mathrm{L}$ (Uyak, 2006) and Antalya in the range of 11-23 $\mu \mathrm{g} / \mathrm{L}$ (Kitis et al., 2010). As shown in Table 4, drinking of tap water results in higher exposure due to the high THM contents in contrast to bottled water. Drinking bottled water at work did not seem to significantly reduce exposure levels due to the low drinking water consumption rate at work. Descriptive statistics of the ingestion exposure estimates are presented in Supplementary Material (SM) Table S1.

Exposure to THMs through inhalation route should also be 
Table 4

Median THM chronic daily intake levels (mg/kg-day).

\begin{tabular}{|c|c|c|c|c|c|}
\hline & & Chloroform & BDCM & DBCM & Bromoform \\
\hline \multirow[t]{3}{*}{ Ingestion } & Scenario 1 & $2.08 \times 10^{-6}$ & $3.65 \times 10^{-6}$ & $7.12 \times 10^{-6}$ & $7.81 \times 10^{-6}$ \\
\hline & Scenario 2 & $1.72 \times 10^{-6}$ & $2.93 \times 10^{-6}$ & $6.18 \times 10^{-6}$ & $6.87 \times 10^{-6}$ \\
\hline & Scenario 3 & $4.90 \times 10^{-7}$ & $1.09 \times 10^{-7}$ & $1.38 \times 10^{-7}$ & $1.39 \times 10^{-6}$ \\
\hline \multirow[t]{3}{*}{ Dermal } & Scenario 1 & $3.04 \times 10^{-10}$ & $4.41 \times 10^{-10}$ & $6.38 \times 10^{-9}$ & $1.48 \times 10^{-9}$ \\
\hline & Scenario 2 & $1.79 \times 10^{-10}$ & $2.58 \times 10^{-10}$ & $3.76 \times 10^{-9}$ & $8.70 \times 10^{-10}$ \\
\hline & Scenario 3 & $1.56 \times 10^{-10}$ & $2.25 \times 10^{-10}$ & $3.32 \times 10^{-9}$ & $7.58 \times 10^{-10}$ \\
\hline \multirow[t]{3}{*}{ Inhalation } & Scenario 1 & $4.92 \times 10^{-6}$ & $5.94 \times 10^{-6}$ & $1.29 \times 10^{-5}$ & $1.12 \times 10^{-5}$ \\
\hline & Scenario 2 & $2.90 \times 10^{-6}$ & $3.50 \times 10^{-6}$ & $7.59 \times 10^{-6}$ & $6.62 \times 10^{-6}$ \\
\hline & Scenario 3 & $2.57 \times 10^{-6}$ & $3.11 \times 10^{-6}$ & $6.73 \times 10^{-6}$ & $5.87 \times 10^{-6}$ \\
\hline
\end{tabular}

investigated because of their volatility. Showering, bathing and swimming in indoor pools are the main activities that result in the THMs exposure through inhalation route (Chowdhury et al., 2014). Showering and/or bathing are a life-long daily activity from birth to death. The health risks of THMs through the inhalation could be higher than the other exposure pathways (Little, 1992; Uyak, 2006). In this context, determination of health risk via inhalation is as important as for ingestion route. Dermal exposure was estimated for two media: water and air. Dish washing, hand washing, and showering were selected as the main pathways of dermal route to THMs from water (Lin and Hoang, 2000; Chowdhury, 2013). Showering is the main daily activity that results in dermal exposure to THMs from air (Kerger et al., 2000). The mean, median, and 95th percentile durations determined from the questionnaire survey for hand washing were $0.182,0.150$, and $0.363 \mathrm{~h}$ / day, respectively. The mean, median, and 95th percentile durations of dish washing were $0.502,0.333$, and $0.880 \mathrm{~h} /$ day, respectively. Duration of showering could not be determined from the questionnaire survey; therefore, it was taken from the Exposure Factors Handbook (USEPA, 2011). The mean, median and 95th percentile durations for showering were $0.338,0.300,0.573 \mathrm{~h} /$ day, respectively. The estimated dermal exposures are shown in SM Tables S2-S4 for water pathways and in Table S5 for the main inhalation pathway, showering. The estimated exposures show that overlooking inhalation very likely to result in underestimation of aggregate exposure because, estimated inhalation exposure (median values for chloroform, BDCM, DBCM, and bromoform are $2.57 \times 10^{-6}, \quad 3.11 \times 10^{-6}, \quad 6.73 \times 10^{-6}, \quad$ and $5.87 \times 10^{-6} \mathrm{mg} / \mathrm{kg}$-day, respectively) is as high as ingestion exposure (median values for chloroform, BDCM, DBCM, bromoform are $2.08 \times 10^{-6}, 3.65 \times 10^{-6}, 7.12 \times 10^{-6}$, and $7.81 \times 10^{-6} \mathrm{mg} / \mathrm{kg}$-day, respectively), and higher than dermal exposure (median values for chloroform, BDCM, DBCM, and bromoform are $1.56 \times 10^{-10}$, $2.25 \times 10^{-10}, 3.32 \times 10^{-9}$, and $7.58 \times 10^{-10} \mathrm{mg} / \mathrm{kg}$-day, respectively).

\subsection{Carcinogenic risk}

Carcinogenic risk (CR) assessment was conducted associated with the estimated exposures. The upper-bound (95th percentile) and central tendency (the mean and median) risk estimations were made for the considered exposure scenarios. In the first scenario, it is assumed that people drank tap water both at home and work. In the second scenario, it was assumed that people drank tap water at home and bottled water at work. In third scenario, it was assumed that people drank bottled water both at home and work. The 1st and 3rd scenarios represented the worst and best cases, respectively, as bottled water contained much less THMs compared to tap water. Risk values were evaluated in four categories (Legay et al., 2011): $\mathrm{CR} \leq 10^{-6}$ considered as there is no risk (safe zone), $10^{-6}<\mathrm{CR}<10^{-5}$ considered as acceptable risk zone, $10^{-5}<\mathrm{CR}<10^{-4}$ considered as low priority risk zone, and $\mathrm{CR} \geq 10^{-4}$ considered as unacceptable risk and high priority risk zone.

CR was estimated for each considered exposure pathway for all scenarios (Fig. 1). In the first (worst-case) scenario, the mean, median,

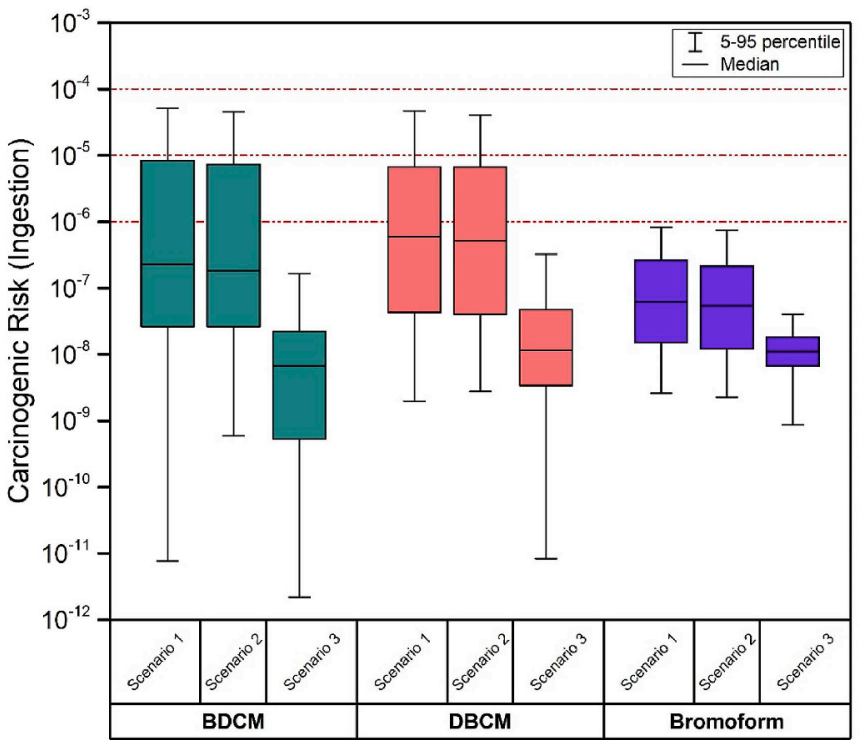

Fig. 1. THM carcinogenic risk levels associated with ingestion.

and 95th percentile CR values for ingestion route spanned from safe to low priority zone for both $\operatorname{BDCM}\left(9.87 \times 10^{-6}, 2.26 \times 10^{-7}\right.$ and $5.07 \times 10^{-5}$, respectively) and DBCM $\left(9.37 \times 10^{-6}, 5.98 \times 10^{-7}\right.$ and $4.57 \times 10^{-5}$, respectively). CR values of bromoform through ingestion were estimated in safe zone even for the worst-case scenario with the mean, median, and 95th percentile values of $2.07 \times 10^{-7}, 6.17 \times 10^{-8}$ and $7.92 \times 10^{-7}$, respectively. In the second scenario, the estimated mean, median, and 95th percentile CR levels of BDCM for ingestion route were $8.56 \times 10^{-6}, 1.82 \times 10^{-7}, 4.56 \times 10^{-5}$, respectively, which span again from safe to low priority zones. The mean, median and 95th percentile CR values of DBCM through ingestion were estimated as $8.19 \times 10^{-6}, 5.20 \times 10^{-7}, 3.97 \times 10^{-5}$, respectively, which again spanned from safe to low priority zones. Estimated CR of bromoform through ingestion route, on the other hand, were lower than BDCM and DBCM, and stayed in the safe zone even at 95th percentile level. The CR values of all three THMs were estimated to be in the safe zone even at 95th percentile in the 3rd (best-case) scenario with the highest value of $2.44 \times 10^{-7}$ for DBCM. The estimated CR values of chloroform, BDCM, DBCM, bromoform through ingestion route by Chowdhury et al. (2014) were in the range of $1.31 \times 10^{-7}$. $1.35 \times 10^{-5}$. Panyakapo et al. (2008) estimated the CR of THM compounds in high and average concentrations through ingestion route in the ranges of $2.17 \times 10^{-6}-9.40 \times 10^{-5}$ and $1.05 \times 10^{-6}-$ $4.65 \times 10^{-5}$, respectively. Uyak (2006) estimated the highest CR of THMs through ingestion route as $2.10 \times 10^{-5}$ associated with BDCM in Istanbul (Turkey). Order of the mean CR levels were estimated from high to low as DBCM, BDCM, and bromoform in Istanbul (Turkey) (Uyak, 2006). Relatively low CR levels were observed through ingestion route in this study due to the low THM concentrations in tap water of 


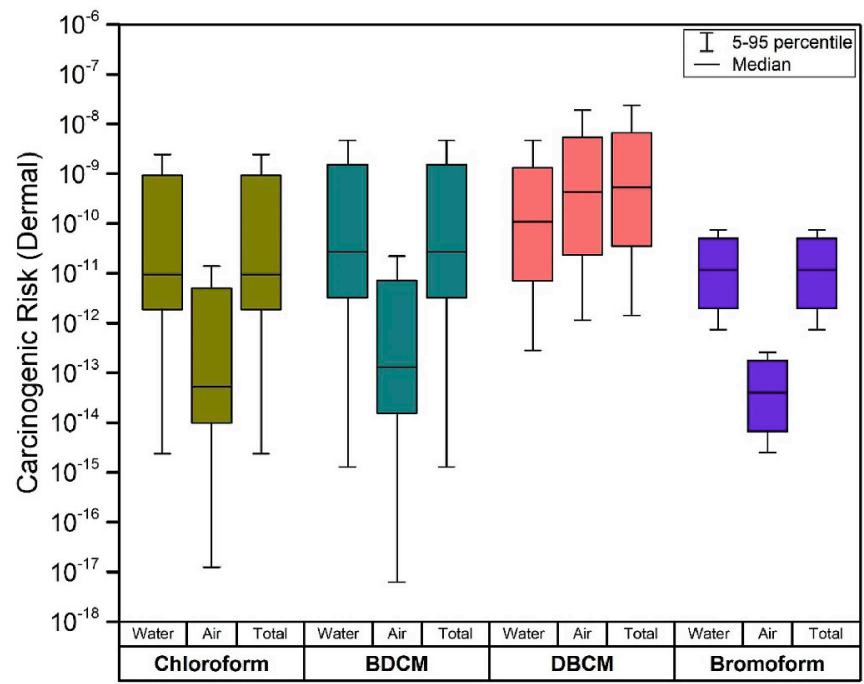

Fig. 2. Carcinogenic risk levels of THMs through dermal exposure (Scenario 1) from water.

Izmir and commercial bottled water.

Dermal CR levels from water were estimated based on tap water concentrations for dish and hand washing, and heated water concentrations for showering pathways. The median values of $\mathrm{CR}$ of chloroform, BDCM, DBCM, and bromoform from water through dermal route in Scenario 1 were estimated in the range of safe zone, which spans from $8.52 \times 10^{-12}$ to $1.10 \times 10^{-10}$. The dermal CR values from air were estimated based on the modeled bathroom air concentrations during showering. The estimated dermal CR from air is lower than that from water except for DBCM (for which CR levels from water and air are similar). Only DBCM stood out due to relatively higher risk levels associated with dermal exposure from air during showering. Dermal exposure via air is very small compared to water, therefore total dermal $\mathrm{CR}$ is dominated by the water pathways. All estimated $\mathrm{CR}$ values were under the safe zone limit value ( $C R<10^{-6}$ ) for all water and air exposure pathways even for their sum at 95th percentile level (Fig. 2). These findings are consistent with other studies in the literature (Wang et al., 2007a, b; Basu et al., 2011).

CR of THMs through inhalation during showering are shown in

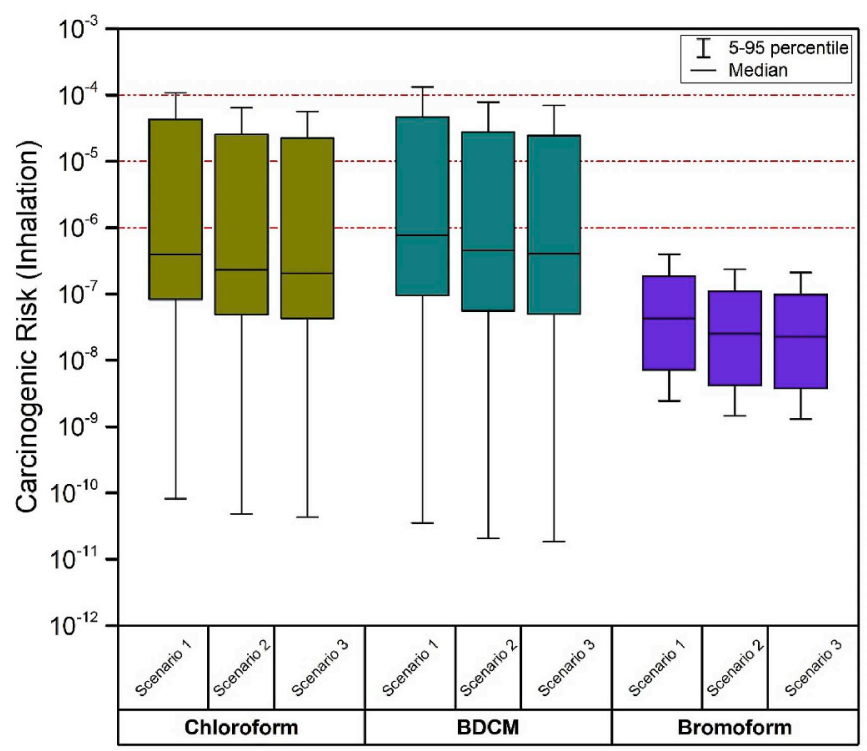

Fig. 3. Carcinogenic risk levels of THMs through inhalation for showering.

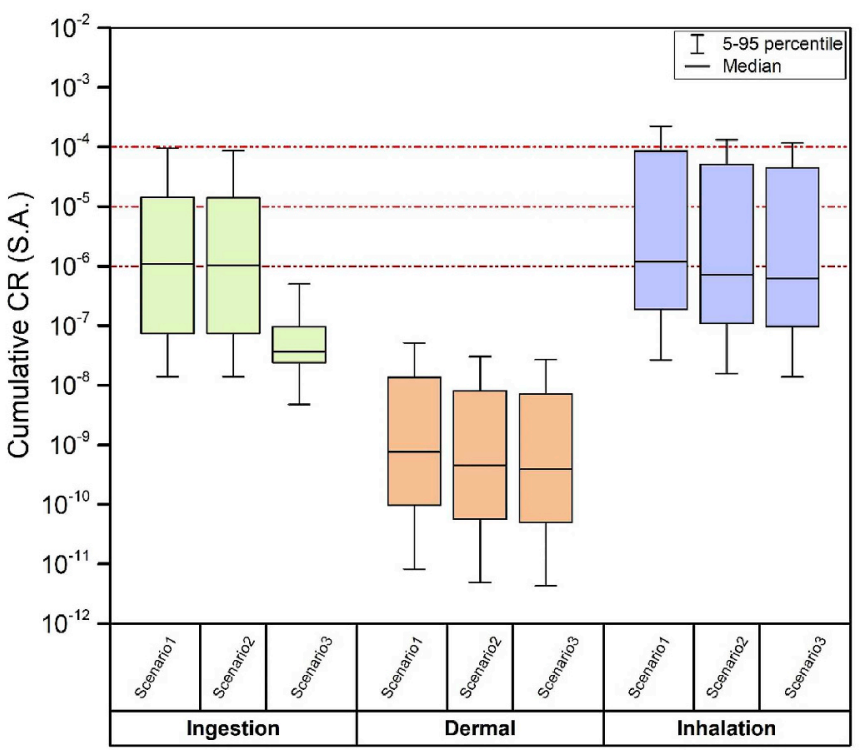

Fig. 4. Cumulative carcinogenic risk of THMs estimated with simple addition.

Fig. 3. These scenarios were created based on the 95th percentile, mean, and median (Scenario 1,2 and 3, respectively) showering durations (34.4, 20.3, and $18.0 \mathrm{~min}$, respectively) obtained from the questionnaire survey. While all the estimations for bromoform and the medians of the remaining two THMs were in the safe zone, the mean and 95th percentile CR levels were $>10^{-5}$ for the two THMs indicating low priority risks with only the highest value of $1.07 \times 10^{-4}$ for chloroform (in Scenario 1) emerging in the high priority zone. CR levels of THMs through inhalation route are relatively high due to their volatility (Uyak, 2006; Basu et al., 2011). In the literature, chloroform is the main contributor to CR through inhalation route (Uyak, 2006; Wang et al., 2007a, b; Basu et al., 2011), however, chloroform and BDCM were estimated as the main contributors of CR through inhalation in this study with 45.2 and $54.6 \%$.

\subsection{Cumulative risks}

Cumulative $\mathrm{CR}$ values obtained by simple addition are shown in Fig. 4. Cumulative CR associated with dermal exposure is lower than those of ingestion and inhalation routes. Cumulative risks in Scenario 3 for ingestion were all in safe zone, while those in Scenarios 1 and 2 spanned from safe to low priority zones. It has been estimated that the consumption of bottled water at the work did not significantly affect the cumulative risk due to the low intake rate at work $(0.59 \mathrm{~L} /$ day $)$ compared to that at home $(1.22 \mathrm{~L} /$ day $)$. However, consumption of bottled water considerably decreases the cumulative risk due to the low THM content of bottled water, which shows that mitigation measures to reduce DBPs in Izmir tap water could play a significant role in reducing the associated risks. Cumulative $\mathrm{CR}$ values through dermal exposure were estimated in safe zone. THM exposure through dermal contact is generally low due to the low permeability coefficients of THM species and short exposure durations. Cumulative CR levels of all scenarios through inhalation route estimated in a wider range than ingestion and dermal exposures. Median CR levels of Scenario 1, 2, and 3 through inhalation route were estimated near the boundary of safe zone, however 95th CR levels were estimated around the boundary of high priority zone. As shown in Fig. 4, the highest risk of cancer occurs with inhalation route during showering and oral route with drinking from tap water.

Cumulative risks estimated by CRPF method resulted in categorization of risk mainly in the safe zone except 95th percentile values of inhalation and ingestion scenarios that involve consumption of tap 


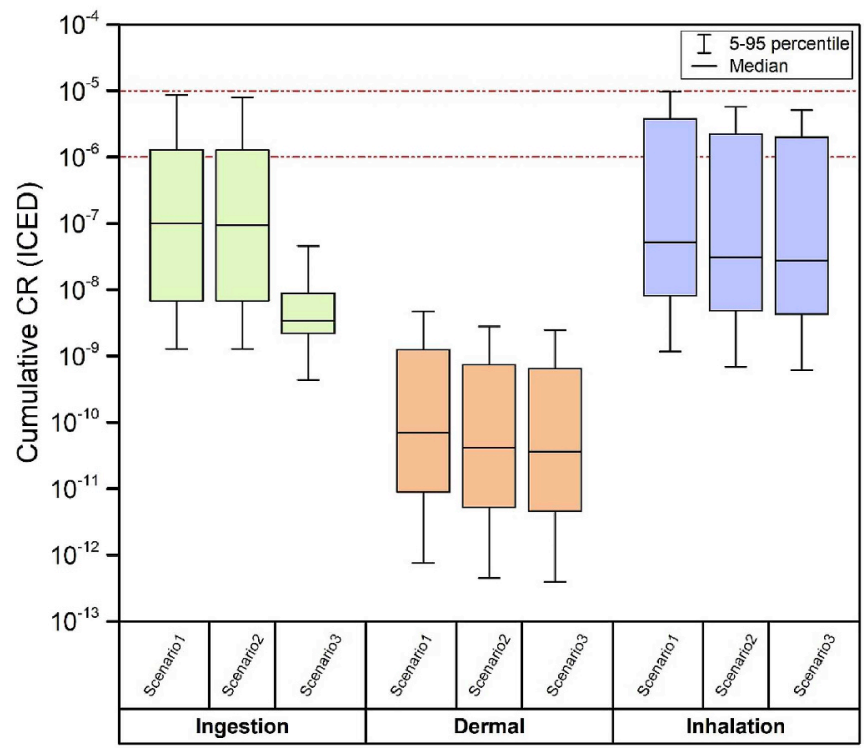

Fig. 5. Cumulative carcinogenic risk of THMs estimated with CRPF.

water. Bottled water consumption at work in Scenario 2 did not decrease the cumulative $\mathrm{CR}$ considerably. However, bottled water consumption both at home and work significantly reduced cumulative CR level of ingestion route. Although the majority of people, which is less than $75 \%$, exposed to THMs by inhalation are in safe zone, the remaining $20 \%$ up to 95 th percentile are in the acceptable risk zone in the worst-case (Scenario 1). Estimated cumulative risk levels by CRPF method were lower than those estimated by simple addition method (Fig. 5). SA/CRPF ratio are 10.88, 10.88, and 22.80 for ingestion, dermal, and inhalation, respectively. This difference is due to the use of maximum likelihood estimate (MLE) of the SF for the index chemical (BDCM) for estimation of the cumulative risk with the class ICED instead of the SF value used in the calculation of RPF values as suggested by Teuschler et al. (2004). If the $95 \%$ upper bound SF $\left(6.2 \times 10^{-2}\right.$ $[\mathrm{mg} / \mathrm{kg} \text {-day }]^{-1}$ ) is used both in RPF and cumulative risk calculation instead of the MLE value $\left(5.7 \times 10^{-3}\left[\mathrm{mg} / \mathrm{kg}\right.\right.$-day $\left.{ }^{-1}\right)$ for cases such as in this study where there are only compounds, all of which can be assumed to have a common Mode of Action (MoA) so that dose addition is used, both methods (response addition and dose addition, CRPF in this study) would result in the same level of cumulative risk because mathematically the two methods are essentially the same (Eq. (15)).

This study used THM concentrations measured by Kavcar et al. (2006), which can be justified by comparing them to those measured by the local authorities since then. Total THM concentrations in Izmir is regularly measured at six sampling points, and published on the internet by water supply authority of the city (IZSU). So, THM concentrations used in this study and those measured and published by IZSU between 2013 and 2017 were compared. Descriptive statistics and results of Mann-Whitney test used for comparison are presented in SM Tables S7 and S8, respectively. The difference is significant, indicating that the latter concentrations (IZSU, 2013-17) are higher than the former (Kavcar et al., 2006), which may make the exposure-risk levels found in this study underestimations. Ratio of the mean concentrations of the former and the latter data sets is 0.70 . However, the latter concentrations published by IZSU are measured at water supply storage points in the distribution system, but not at the tap, therefore they are probably higher than the levels people are actually exposed to, which may cancel out the underestimation.

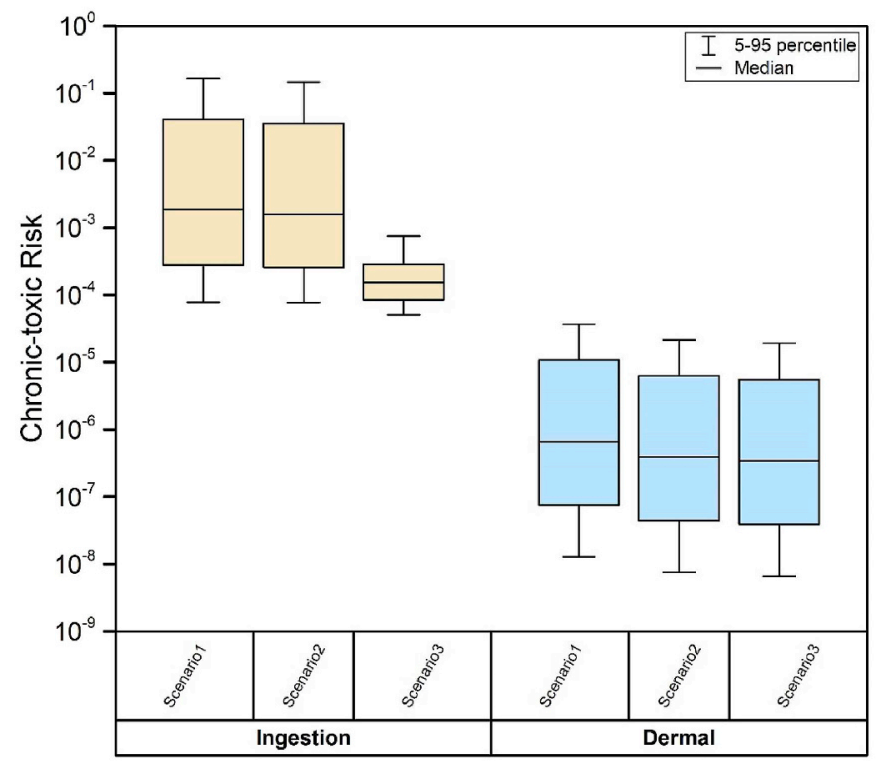

Fig. 6. Cumulative chronic-toxic risk of THMs (HI).

$$
\begin{gathered}
\left(S F_{1} \times D_{1}\right)+\left(S F_{2} \times D_{2}\right)+\left(S F_{3}\right. \\
\left.\times D_{3}\right)=\left[\left(\frac{S F_{1}}{S F_{1}} \times I C E D_{1}\right)+\left(\frac{S F_{2}}{S F_{1}} \times I C E D_{2}\right)\right. \\
\left.+\left(\frac{S F_{3}}{S F_{1}} \times I C E D_{3}\right)\right] \times S F_{1}
\end{gathered}
$$

\subsection{Chronic-toxic risk assessment}

Cumulative Chronic-Toxic Risks (CTR) were also assessed in this study using Hazard Index (HI) (Fig. 6). If HI values are greater than the threshold value of ' 1 ', adverse health effects are possible, and depending on the levels further investigation is required. HI values of THM through ingestion and dermal contact are lower than the threshold. Similar to the carcinogenic risks values, the lowest CTR was estimated for the dermal exposure. However, CTR associated with ingestion were estimated to be below the threshold, while its carcinogenic risks were up to high priority risk boundary of $10^{-4}$. CTR were not estimated for inhalation since no RfC values were available.

\section{Conclusions}

Similar carcinogenic risk (CR) levels were estimated for inhalation and ingestion, while risks associated with dermal exposure pathways were considerably lower. CR by ingestion pathway is mainly due to BDCM and DBCM contents in tap water, and bromoform content in bottled water. CR and chronic-toxic risk (CTR) levels were low for the dermal exposure route, and at similar levels for all THM species in water pathways. However, CR levels due to dermal exposure from air mainly occurs by DBCM. Although the permeability coefficient is relatively low compared to that of chloroform, the relatively high slope factor of DBCM renders higher CRs. High CR and CTR by inhalation route were estimated due to the volatility of the THMs from water heated to $40{ }^{\circ} \mathrm{C}$, even without the contribution of DBCM due to unavailable slope factor. Therefore, the estimated levels of CR for inhalation is due to the chloroform volatilization from heated water during showering. Low bromoform exposure was estimated due to relatively lower volatility and lower concentrations in the modeled bathroom air. As a conclusion, it has been determined that THM levels in tap water increase both carcinogenic and chronic-toxic risks through ingestion and inhalation routes, indicating that mitigation measures are 
needed. Cumulative CR levels were estimated using simple addition (SA) and CRPF. Higher CR levels were estimated using SA due to the use of the maximum likelihood estimate for slope factor (SF) of the index chemical for cumulative risk calculation rather than the upper-bound $\mathrm{SF}$ value in CRPF method. Otherwise, the two methods should estimate the same cumulative risk levels. Majority of the cumulative CR levels estimated with CRPF method both for ingestion and inhalation were below the de Minimis risk level of $10^{-6}$, while all 95th percentile values were below $10^{-5}$, which therefore can be considered as acceptable, whereas those estimated with SA were higher with median levels around $10^{-6}$ and 95th percentile levels reaching $10^{-4}$, indicating priority risk levels. Since the slope factor of each compound is different, an environmental/public health management plan should be established based on individual compound concentrations not total THM measured at the consumer tap, and associated cumulative carcinogenic risks. The authorities should estimate and publish the cumulative risks periodically, rather than the concentrations.

\section{Declarations of interest}

None.

\section{Acknowledgements}

We thank Dr. Figen Tokatli for the help in data analysis. The dataset used in this study was collected in projects supported by the Turkish Scientific and Technological Research Council (TUBITAK) Grant\# IÇTAG-Ç077 and Izmir Institute of Technology Grant\# BAP-2003-42.

\section{Appendix A. Supplementary data}

Supplementary data to this article can be found online at https:// doi.org/10.1016/j.jenvman.2018.10.009.

\section{References}

Aldrich, T.E., Peoples, A.J., 1982. Malignant melanoma and drinking water contamination. Bull. Environ. Contam. Toxicol. 28, 519-523.

Basu, M., Gupta, S.K., Singh, G., Mukhopadhyay, U., 2011. Multi-route risk assessment from trihalomethanes in drinking water supplies. Environ. Monit. Assess. 178, 121-134. https://doi.org/10.1007/s10661-010-1677-z.

Batterman, S., Huang, A.-T., Wang, S., Zhang, L., 2000. Reduction of ingestion exposure to trihalomethanes due to volatilization. Environ. Sci. Technol. 34 (20), 4418-4424. https://doi.org/10.1021/es991304s.

CalEPA, 2018. https://oehha.ca.gov/chemicals/bromodichloromethane (Retrieved date: 01.01.2018).

Cantor, K.P., Hoover, R., Mason, T.J., McCabe, L.J., 1978. Associations of cancer mortality with halomethanes in drinking water. J. Natl. Cancer Inst. 61 (4), 979-985.

Cantor, K.P., Hoover, R., Hartge, P., Mason, T.J., Silverman, D.T., Altman, R., Austin, D.F., Child, M.A., Key, C.R., Marrett, L.D., et al., 1987. Bladder cancer, drinking water source, and tap water consumption: a case-control study. J. Natl. Cancer Inst. 79 (6), 1269-1279.

Cetin, B., Yurdakul, S., Gungormus, E., Ozturk, F., Sofuoglu, S.C., 2018. Source apportionment and carcinogenic risk assessment of passive air sampler-derived PAHs and PCBs in a heavily industrialized region. Sci. Total Environ. 633, 30-41. https://doi. org/10.1016/j.scitotenv.2018.03.145.

Choudhury, H., Hertzberg, R., Rice, G., Cogliano, J., Mukerjee, D., Teuschler, L., Doyle E., Woo, Y., Schoeny, R., 2000. Supplementary Guidance for Conducting Health Risk Assessment of Chemical Mixtures. Risk Assessment Forum, pp. 209. Available at: http://cfpub.epa.gov/ncea/risk/recordisplay.cfm?deid = 20533, Accessed date: 1 May 2018.

Chowdhury, S., 2013. Exposure assessment for trihalomethanes in municipal drinking water and risk reduction strategy. Sci. Total Environ. 463-464, 922-930. https://doi. org $/ 10.1016 /$ j.scitotenv.2013.06.104

Chowdhury, S., Champagne, P., 2009. Risk from exposure to trihalomethanes during shower: probabilistic assessment and control. Sci. Total Environ. 407 (5), 1570-1578. https://doi.org/10.1016/j.scitotenv.2008.11.025.

Chowdhury, S., Al-hooshani, K., Karanfil, T., 2014. Disinfection byproducts in swimming pool: occurrences, implications and future needs. Water Res. 53, 68-109. https://doi. org /10.1016/j.watres.2014.01.017.

Dumanoglu, Y., Gaga, E.O., Gungormus, E., Sofuoglu, S.C., Odabasi, M., 2017. Spatial and seasonal variations, sources, air-soil exchange, and carcinogenic risk assessment for PAHs and PCBs in air and soil of Kutahya, Turkey, the province of thermal power plants. Sci. Total Environ. 580, 920-935. https://doi.org/10.1016/j.scitotenv.2016. 12.040 .
Gallagher, S.S., Rice, G.E., Scarano, L.J., Teuschler, L.K., Bollweg, G., Martin, L., 2015. Cumulative risk assessment lessons learned: a review of case studies and issue papers. Chemosphere 120, 697-705. https://doi.org/10.1016/j.chemosphere.2014.10.030.

Gan, W., Guo, W., Mo, J., He, Y., Liu, Y., Liu, W., Liang, Y., Yang, X., 2013. Science of the Total Environment the occurrence of disinfection by-products in municipal drinking water in China's Pearl River Delta and a multipathway cancer risk assessment. Sci. Total Environ. 447, 108-115. https://doi.org/10.1016/j.scitotenv.2012.12.091.

Gungormus, E., Tuncel, S., Hakan, T.L., Sofuoglu, S.C., 2014. Inhalation and dermal exposure to atmospheric polycyclic aromatic hydrocarbons and associated carcinogenic risks in a relatively small city. Ecotoxicol. Environ. Saf. 108, 106-113. https://doi. org/10.1016/j.ecoenv.2014.06.015.

Harman, B.I., Tanacan, E., Genisoglu, M., Kaplan-Bekaroglu, S.S., Ates, N., Yiğit, N.Ö. Sardohan-Koseoglu, T., Kanan, A.A.S., 2017. Yüzme havuzlarında karbon Bazlı dezenfeksiyon yan ürünlerinin oluşumu. DEU FMD 19 (55), 63-78. https://doi.org/10. 21205/deufmd.2017195506.

Hua, G., Reckhow, D.A., 2008. Hydrophobicity and molecular size distribution of unknown TOX in drinking water. J. Environ. Eng. 134 (3), 152-160. https://doi.org/10 1061/(ASCE)0733-9372(2008)134:3(152).

Kavcar, P., Odabasi, M., Kitis, M., Inal, F., Sofuoglu, S.C., 2006. Occurrence, oral exposure and risk assessment of volatile organic compounds in drinking water for Izmir. Water Res. 40 (17), 3219-3230. https://doi.org/10.1016/j.watres.2006.07.002.

Kerger, B.D., Schmidt, C.E., Paustenbach, D.J., 2000. Assessment of airborne exposure to trihalomethanes from tap water in residential showers and baths. Risk Anal. 20 (5), 637-651. https://doi.org/10.1111/0272-4332.205058.

Kinani, A., Kinani, S., Bouchonnet, S., 2016. Formation and determination of organohalogen by-products in water. Part III. Characterization and quantitative approaches. Trac. Trends Anal. Chem. 85, 295-305. https://doi.org/10.1016/j.trac.2016.09.013.

Kitis, M., Yigita, N.O., Harmana, B.I., Muhammetoglu, H., Muhammetoglu, A., Karadirek, I.E., Demirel, I., Ozdenc, T., Palancic, I., 2010. Occurrence of trihalomethanes in chlorinated groundwaters with very low natural organic matter and bromide concentrations. Environ. Forensics 11 (3), 264-274. https://doi.org/10.1080/15275922. 2010.495935.

Krasner, S.W., 2009. The formation and control of emerging disinfection by-products of health concern. Phil. Trans. R. Soc. A. 367, 4077-4095. https://doi.org/10.1098/ rsta.2009.0108.

Lambert, J.C., Lipscomb, J.C., 2007. Mode of action as a determining factor in additivity models for chemical mixture risk assessment. Regul. Toxicol. Pharmacol. 49 (3), 183-194. https://doi.org/10.1016/j.yrtph.2007.07.002

Lee, S.C., Guo, H., Lam, S.M., Lau, S.L., 2004. Multipathway risk assessment on disinfection by-products of drinking water in Hong Kong. Environ. Res. 94 (1), 47-56. https://doi.org/10.1016/S0013-9351(03)00067-7.

Legay, C., Rodriguez, M.J., Sadiq, R., Sérodes, J.B., Levallois, P., Proulx, F., 2011. Spatial variations of human health risk associated with exposure to chlorination by-products occurring in drinking water. J. Environ. Manag. 92 (3), 892-901. https://doi.org/10. 1016/j.jenvman.2010.10.056.

Lin, T.F., Hoang, S.W., 2000. Inhalation exposure to THMs from drinking water in south Taiwan. Sci. Total Environ. 246 (1), 41-49.

Little, J.C., 1992. Applying the two-resistance theory to contaminant volatilization in showers'. Environ. Sci. Technol. 26 (7), 1341-1349. https://doi.org/10.1021/ es00031a010.

Livingston, E.H., Lee, S., 2001. Body surface area prediction in normal-weight and obese patients. Am J Physiol Metab 281 (3), E586-E591.

Nazir, M., Khan, F.I., 2006. Human health risk modeling for various exposure routes of trihalomethanes (THMs) in potable water supply. Environ. Model. Software 21 (10), 1416-1429. https://doi.org/10.1016/j.envsoft.2005.06.009.

Nicholson, B.C., Maguire, B.P., Burslll, D.B., 1984. Henry's law constants for the trihalomethanes: effects of water composition and temperature. Environ. Sci. Technol. 18 (7), 518-521. https://doi.org/10.1021/es00125a006.

Niu, Z., Zhang, X., Zhang, Y., 2015. Using physiologically based pharmacokinetic models to estimate the health risk of mixtures of trihalomethanes from reclaimed water. J. Hazard Mater. 285, 190-198.

Official Gazette, 2013. Regulation on Water Intended for Human Consumption. Re-Ga: 28580.

Pan, S., An, W., Li, H., Su, M., Zhang, J., Yang, M., 2014. Cancer risk assessment on trihalomethanes and haloacetic acids in drinking water of China using disabilityadjusted life years. J. Hazard Mater. 280, 288-294.

Panyakapo, M., Soontornchai, S., Paopuree, P., 2008. Cancer risk assessment from exposure to trihalomethanes in tap water and swimming pool water. J. Environ. Sci. 20 (3), 372-378. https://doi.org/10.1016/S1001-0742(08)60058-3.

Pardakhti, A.R., Bindhendi, G.R.N., Torabian, A., Karbassi, A., Yunesian, M., 2011. Comperative cancer risk assessment of THMs in drinking water from well water sources and surface water sources. Environ. Monit. Assess 179, 499-507. https://doi. org/10.1007/s10661-010-1752-5.

Pereira, M.A., Herren, S.L., Britt, A.L., Khoury, M.M., 1982. Initiation/promotion bioassay in rat liver: use of gamma glutamyltranspeptidase-positive foci to indicate carcinogenic activity. Toxicol. Pathol. 10 (2), 11-18. https://doi.org/10.1177/ 019262338201000205 .

Siddique, A., Saied, S., Mumtaz, M., Hussain, M.M., Khwaja, H.A., 2015. Multipathways human health risk assessment of trihalomethane exposure through drinking water Ecotoxicol. Environ. Saf. 116, 129-136. https://doi.org/10.1016/j.ecoenv.2015.03. 011.

Stalter, D., O'Malley, E., von Gunten, U., Escher, B.I., 2016. Fingerprinting the reactive toxicity pathways of 50 drinking water disinfection by-products. Water Res. 91 19-30. https://doi.org/10.1016/j.watres.2015.12.047.

Teuschler, L.K., Rice, G.E., Wilkes, C.R., Lipscomb, J.C., Power, F.W., 2004. A feasibility study of cumulative risk assessment methods for drinking water disinfection by- 
product mixtures. J. Toxicol. Environ. Health Part A 67 (8-10), 755-777. https://doi. org/10.1080/15287390490428224.

Thiriat, N., Paulus, H., Le Bot, B., Glorennec, P., 2009. Exposure to inhaled THM: comparison of continuous and event-specific exposure assessment for epidemiologic purposes. Environ. Int. 35 (7), 1086-1089.

Thomas, O., Burgess, C., 2017. In: Edition, S. (Ed.), UV-visible Spectrophotometry of Water and Wastewater. Elsevier ISBN: 9780444638977.

Ugranli, T., Gungormus, E., Kavcar, P., Demircioglu, E., Odabasi, M., Sofuoglu, S.C., Lammel, G., Sofuoglu, A., 2016. POPs in a major conurbation in Turkey: ambient air concentrations, seasonal variation, inhalation and dermal exposure, and associated carcinogenic risks. Environ. Sci. Pollut. Res. Int. 23 (22), 22500-22512. https://doi. org/10.1007/s11356-016-7350-5.

U.S. Environmental Protection Agency (EPA, 2011. Exposure Factors Handbook: 2011 Edition. National Center for Environmental Assessment, Washington, DC EPA/600/R09/052F. Available from: the National Technical Information Service, Springfield, VA, and online at. http://www.epa.gov/ncea/efh.

USEPA, 1992. Guidelines for Exposure Assessment. U.S. Environmental Protection Agency, Risk Assessment Forum, Washington, DC EPA/600/Z-92/001.

USEPA, 2000. Conducting a Risk Assessment of Mixtures of Disinfection By-products (DBPs) for Drinking Water Treatment Systems. U.S. Environmental Protection Agency, Washington, DC EPA/600/R-03/040.

USEPA, 2002. Guidance on Cumulative Risk Assessment of Pesticide Chemicals that Have a Common Mechansim of Toxicity. U.S. Environmental Protection Agency Available at: https://www.epa.gov/sites/production/files/2015-07/documents/guidance_on_ common mechanism.pdf.

USEPA, 2003. Framework for Cumulative Risk Assessment. U.S. Environmental Protection Agency, pp. 1-129 EPA/630/P-02/001F.

USEPA, 2006. Stage 1 Disinfectants and Disinfection Byproducts Rule Laboratory Quick Reference Guide, Water. U.S. Environmental Protection Agency.

USEPA, 2018. https://www.epa.gov/iris, Accessed date: 1 January 2018.

Uyak, V., 2006. Multi-pathway risk assessment of trihalomethanes exposure in Istanbul drinking water supplies. Environ. Int. 32 (1), 2-21. https://doi.org/10.1016/j.envint. 2005.03.005.

Viana, R.B., Cavalcante, R.M., Braga, F.M.G., Viana, A.B., Araujo, J.C., 2009. Risk assessment of trihalomethanes from tap water in Fortaleza, Brazil. Environ. Monit. Assess. 151, 317-325. https://doi.org/10.1007/s10661-008-0273-y.

Villanueva, C.M., Cantor, K.P., Cordier, S., Jaakkola, J.J., King, W.D., Lynch, C.F., Porru, S., Kogevinas, M., 2004. Disinfection byproducts and bladder cancer. Epidemiology 15 (3), 357-367. https://doi.org/10.1097/01.ede.0000121380.02594.fc.

Wang, G.-S., Deng, Y.-C., Lin, T.-F., 2007a. Cancer risk assessment from trihalomethanes in drinking water. Sci. Total Environ. 387 (1-3), 86-95. https://doi.org/10.1016/j. scitotenv.2007.07.029.

Wang, W., Ye, Y., Yang, L., Li, Y., Wang, Y., 2007b. Risk assessment on disinfection byproducts of drinking water of different water sources and disinfection processes. Environ. Int. 33 (2), 219-225. https://doi.org/10.1016/j.envint.2006.09.009. 